\title{
CORRESPONDENCE
}

\section{The mental and psychological problems in left-behind children in China}

Pediatric Research (2020) 87:802-803; https://doi.org/10.1038/s41390019-0449-x

We aimed to present the conditions experienced by liu shou er tong (left-behind children, LBC) in order to increase public awareness. China's rapid economic development and urbanization in the past 20 years have created both major economic progress and the LBC situation. The recent national survey in 2013 put the number of LBC at 61 million. Studies have shown that $\mathrm{LBC}$ are more likely to experience mental and psychological problems due to a lack of normal parental care and education. This phenomenon has not adequately attracted attention from parents or from society in general. In addition, there is also a considerable shortage of Chinese pediatricians, especially children's psychiatrists. As such, China is facing a severe situation with regard to children's mental and psychological problems of LBC in the next few years.

China, a country with a population of 1.3 billion, which is the most populous country in the world. China's great achievements in the history of human economic development over the past 40 years, especially over the last 20 years, which set an example for global poverty alleviation. However, China's economic development and urbanization in the past 20 years have also prompted a mass migration of adults from rural to urban areas as they seek improved living conditions. Some have called this the largest migration in human history. ${ }^{1}$ Although some rural migrants bring their families, most parents do not take their children with them because they cannot afford to raise them in the city. Therefore, these children stay in their rural communities to be cared for by a single parent, grandparents, other relatives, or themselves. The departure of these adults has created a new group in rural China known as LBC.

According to national surveys, There were once $\sim 20$ million LBC in China in 2000. In 2008, this number has soared to 58 million and is still rising; a recent (All-China Women's Federation, 2013) survey estimated 61 million LBC $^{2}$-over 3 times the number estimated in 2000, which far more than the total population of England. Only in recent years have LBC begun to draw media and societal attention. However, concerns regarding LBC have mainly focused on their physical health and education, to the neglect of their mental and psychological problems. Long-term separation from parents, a lack of normal parental care, and a lack of education increase the likelihood that LBC experience certain mental and psychological problems, such as depression, loneliness, anxiety, learning disabilities, emotional disorders, and sleep disorders. ${ }^{3}$ These mental and psychological problems are rarely detected early, especially when children are cared for by elderly grandparents. Worse still, psychological challenges are further exacerbated by the poor economic status of rural families, low levels of education, and LBC parents' low levels of cognitive functioning on mental and psychological problems. Parents of LBC usually lack the financial capacity to treat mental and psychological problems and often do not realize that their child has a disease. Some parents even always complain to their children about their relatively limited abilities compared with psychologically healthy children, which can further aggravate the disease and widen the gap between parents and children, causing the children to become even more physically and mentally left behind. This vicious circle is expected to cause an explosion of mental and psychological problems in Chinese children in the next few years.

Problematically, there is also a considerable shortage of Chinese pediatricians. According to the Chinese Medical Doctor Association in 2014, China has $>300$ million children, but there are only 68 specialized children's hospitals and $\sim 258,000$ hospital beds for children. Compared to developed countries, China lacks at least 200,000 pediatricians. ${ }^{4,5}$ Furthermore, unofficial statistics show that fewer than 500 child psychiatrists are currently registered in China. ${ }^{6}$ With so few child psychiatrists, it is impossible to address the psychological problems of the country's 60 million LBC, not to mention those of the nearly 300 million non-left-behind children. Accordingly, China is facing a severe situation with regard to children's mental and psychological problems of LBC in the next few years.

Nowadays, the mental and psychological needs of LBC require attention and action from Chinese society. We are currently carrying out clinical screenings and offering treatment for LBC's mental and psychological problems, as well as training young child psychiatrists.

\section{ACKNOWLEDGEMENTS}

We thank Zheng Zhou, Weili Dang, Hong Zheng, Xiubo Du and Huawei Li in The First Affiliated Hospital of Henan University of Chinese Medicine for their professional guidance.

\section{AUTHOR CONTRIBUTIONS}

Rong-yi Zhou drafted the manuscript. Jiao-jiao Wang contributed to the design and acquisition of data. Bingxiang Ma final approval of the version to be published and offered professional guidance.

\section{ADDITIONAL INFORMATION}

Competing interests: The authors declare no competing interests.

Publisher's note: Springer Nature remains neutral with regard to jurisdictional claims in published maps and institutional affiliations.

Rong-yi Zhou (D) ${ }^{1}$, Jiao-jiao Wang ${ }^{2}$ and Bing-xiang $\mathrm{Ma}^{1}$ ${ }^{1}$ The First Affiliated Hospital of Henan University of Chinese Medicine, Zhengzhou, China and ${ }^{2}$ Henan Provincial People's Hospital, Zhengzhou, China Correspondence: Rong-yi Zhou (zhourongyitcm@sina.com) These authors contributed equally: Rong-yi Zhou, Jiao-jiao Wang 


\section{REFERENCES}

1. Liu, Z., Li, X. \& Ge, X. Left too early: the effects of age at separation from parents on Chinese rural children's symptoms of anxiety and depression. Am. J. Public Health 99, 2049-2054 (2009).

2. All-China Women's Federation. National survey of rural left-behind children and migrant children in China. Beijing. (2013).

3. Zhou, M., Sun, X., Huang, L. et al. Parental migration and left-behind children's depressive symptoms: estimation based on a nationally-representative panel dataset. Int J. Environ. Res Public Health 16, E1069 (2018). pii.
4. Hu, K. J., Sun, Z. Z. \& Rui, Y. J. et al. Shortage of paediatricians in China. Lancet 383, 954 (2014).

5. Chinese Medical Doctor Association. Paediatricians flee away in China (In Chinese). http://www.cmda.gov.cn/xinwen/redianxinwen/2014-01-24/12845.html. Accessed 25 Jan 2014.

6. National child psychiatrists less than 500 in China (In Chinese). http://news.ifeng. com/a/20180823/59949270_0.shtml. 